\title{
CFD Investigation into The Effect of Heave Plate on Vertical Motion Responses of a Floating Jetty
}

\author{
Ahmad Fitriadhy ${ }^{1,}{ }^{*}$, Nur Amira Adam ${ }^{2}$, Nurul Aqilah Mansor ${ }^{2}$, Mohammad Fadhli Ahmad ${ }^{1}$, Ahmad \\ Jusoh $^{3}$, Noraieni Hj. Mokhtar ${ }^{4}$, Mohd Sofiyan Sulaiman ${ }^{3}$
}

1 Programme of Maritime Technology, Faculty of Ocean Engineering Technology and Informatics, Universiti Malaysia Terengganu, Kuala Terengganu, Terengganu, Malaysia

2 Postgraduate Student, Programme of Maritime Technology, Faculty of Ocean Engineering Technology and Informatics, Universiti Malaysia Terengganu, Kuala Terengganu, Malaysia

3 Programme of Environmental Technology, Faculty of Ocean Engineering Technology and Informatics, Universiti Malaysia Terengganu, Kuala Terengganu, Terengganu, Malaysia

4 Programme of Electronic and Instrumentation, Faculty of Ocean Engineering Technology and Informatics, Universiti Malaysia Terengganu, Kuala Terengganu, Terengganu, Malaysia

\section{ARTICLE INFO ABSTRACT}

Article history:

Received 18 March 2020

Received in revised form 17 May 2020

Accepted 22 May 2020

Available online 30 May 2020

\section{Keywords:}

Floating jetty; heave plate; heave motion; draft; wave periods
When a floating jetty experiences an instability due to excessive vertical motions, it may potentially lead to serious consequences such as the loss of life and property. Corresponding to this problem, comprehensive investigation into effect of a heave plate on suppressing the vertical motion of the floating jetty is primarily required. To achieve the objective, a Computational Fluid Dynamics (CFD) simulation approach has been conducted to analyse the vertical motion (heave motion) of the floating jetty, which is equipped with the heave plate. Several parameters such as the effect of wave periods $\left(T_{w}\right)$ and drafts of the floating jetty have been taken into account in the computational simulation. In addition, the heave motion responses of the floating jetty are then quantified through a Response of Amplitude Operators (RAO). The CFD simulation results revealed that the floating jetty incorporated with the heave plate has generally reduced the heave motion of the floating jetty. Here, the RAO of its heave motion has sufficiently decreased up to 20 percent as compared with the case without the heave plate ones. Regardless of the wave periods, meanwhile, the subsequent increase of the floating jetty draft from $0.4 \mathrm{~m}$ to $0.8 \mathrm{~m}$ showed insignificant effect to suppress the RAO of its heave motion. It was merely concluded that the attached structural heave plate on the floating jetty is deemed necessary to reduce its dynamic heave motion responses.

Copyright @ 2020 PENERBIT AKADEMIA BARU - All rights reserved

\section{Introduction}

Nowadays, the application of floating jetty has found more popular compared to the fixed jetty design. According to Niaounakis [1], the floating structure most commonly used due to its inherent

\footnotetext{
* Corresponding author.

E-mail address: a.fitriadhy@umt.edu.my (Ahmad Fitriadhy)
}

https://doi.org/10.37934/cfdl.12.5.2435 
advantages offer, such as have a practical design with more lightweight, durable, corrosion resistance and easy installations process. The floating jetty structure also was compatible with all types of seabed, which is not caused a damage to marine environment and plants growing on the seabed. However, the interaction between the movement of fluid in wave and the floating jetty has a critical hydrodynamics responses due to effectiveness of wave energy absorption Chakrabarti [2]. This condition may lead to a decrease in dock stability and occurred a serious accident during its operation.

In the recent studies, an additional heave plate attached at the bottom of free bodies to reduce the vertical motion responses caused by wave action have been successfully conducted by Holmes et al., [3], Brown et al., [4] and Liang et al., [5]. Tao and Cai [6], Koh and Cho [7], Subbulakshmi et al., [8], Yu et al., [9] and Mecrow and Garvey [10] have studied the effect of the heave plate to the offshore structure. They found that the vertical response at offshore floating structure with heave plate will reduce significantly due to increase of added mass and damping coefficient of the structure. In additional, this structural heave plate also has been applied to a floating breakwater and floating offshore wind turbine. Ishihara et al., [11], reported that the heave motion reduction was up to $50 \%$ at the extreme wave conditions; while increased the stability of the floating structure. However, further investigations about the heave plate application on a floating jetty is rarely seen. Whilst a Computational Fluid Dynamic (CFD) approach for assessing the vertical motion responses on the floating jetty put very demanding requirements with regards to a reliable result. Recent advance in computers, these requirements is possibly satisfied.

In the present study, a Computational Fluid Dynamics (CFD) investigation has been conducted to analyse the vertical motion (heave motion) performances of the floating jetty in waves. This study has provided very interesting computational simulations, whilst a hydrodynamic description underlying the rationale behind the results is explained. To achieve this research objective, several effect of various wave periods from 3 up to 10 seconds associated with two drafts condition of the floating jetty i.e., $0.4 \mathrm{~m}$ and $0.8 \mathrm{~m}$, have been primarily taken into account in the current computational simulation. It should be noted here that a magnitude of the dynamic heave motion responses presented in the form of Response of Amplitude Operators (RAO) of the floating jetty has been comprehensively quantified to predict her heave motion reduction. For conforming the computational prediction, the comparison of the RAO of the heave motion is presented between the floating jetty with and without equipped by the structural heave plate. Here, a CFD software namely Flow-3D is employed through applying unsteady Reynolds-Averaged Navier-Stokes Equation (RANSE); which includes several techniques (TruVOF) to capture the free surface effect. The Response Amplitude Operator (RAO) of heave and pitch motion performances are then accordingly discussed.

\section{Governing Equation}

Here, the main equation use by the CFD regularly is Navier-Stokes equation, which basically includes continuity and momentum equations, Sapee [12]. Basically, two equations in accordance to the law conservation of mass and momentum as clearly expressed in Eqs. (1)-(4). The current CFD simulation is based on the incompressible unsteady RANSE, which employs the volume of fluid (VOF) to solve a free surface model.

\subsection{Continuity and Momentum Equation}

The general mass continuity equation presented in Eq. (1), for a moving object and the comparative VOF function transport equation; where the $\mathrm{V}_{\mathrm{F}}$ is the fractional volume open to flow, $\rho$ 
is the fluid density, $R_{D I F}$ is a turbulent diffusion term, $R_{S O R}$ is a mass sourceand $A_{x}, A_{y}$ and $A_{z}$ is the fractional area open to flow in $\mathrm{x}, \mathrm{y}$ and $\mathrm{z}$-direction, respectively. The coefficient of $\xi$ and $\mathrm{R}$ correspond to the Cartesian coordinate where $\mathrm{R}$ is set to unity and $\xi=0$. The velocity components $(u, v, w)$ are in the coordinate directions $(x, y, z)$ or $\left(r, R_{S O R}, z\right)$ Manual [13].

$V_{F} \frac{\partial \rho}{\partial t}+\frac{\partial}{\partial x}\left(\rho u A_{x}\right)+R \frac{\partial}{\partial y}\left(\rho v A_{y}\right)+\frac{\partial}{\partial z}\left(\rho \omega A_{z}\right)+\xi \frac{\rho u A_{x}}{x}=R_{D I F}+R_{S O R}$

The momentum theory also applies in three fluid velocity components $(u, v, w)$ that has been used in the motion equation as displayed in Eqs. (2)-(4).

$\frac{\partial u}{\partial t}+\frac{1}{V_{F}}\left\{u A_{x} \frac{\partial u}{\partial x}+v A_{y} R \frac{\partial u}{\partial y}+w A_{z} \frac{\partial u}{\partial z}\right\}-\xi \frac{A_{y} v^{2}}{x V_{F}}=-\frac{1}{\rho} \frac{\partial p}{\partial x}+G_{x}+f_{x}-b_{x}-\frac{R_{S O R}}{\rho V_{F}}\left(u-u_{w}-\delta u_{s}\right)$

$\frac{\partial v}{\partial t}+\frac{1}{V_{F}}\left\{u A_{x} \frac{\partial v}{\partial x}+v A_{y} R \frac{\partial v}{\partial y}+w A_{z} \frac{\partial v}{\partial z}\right\}+\xi \frac{A_{y} u v}{x V_{F}}=-\frac{1}{\rho}\left(R \frac{\partial p}{\partial y}\right)+G_{y}+f_{y}-b_{y}-\frac{R_{S O R}}{\rho V_{F}}\left(v-v_{w}-\right.$ $\left.\delta v_{S}\right)$

$\frac{\partial w}{\partial t}+\frac{1}{V_{F}}\left\{u A_{x} \frac{\partial w}{\partial x}+v A_{y} R \frac{\partial w}{\partial y}+w A_{z} \frac{\partial w}{\partial z}\right\}=-\frac{1}{\rho} \frac{\partial p}{\partial z}+G_{z}+f_{z}-b_{z}-\frac{R_{S O R}}{\rho V_{F}}\left(w-w_{w}-\delta w_{S}\right)$

where $\left(G_{x}, G_{y}, G_{z}\right)$ are body accelerations, $\left(f_{x}, f_{y}, f_{z}\right)$ are viscous accelerations and $\left(b_{x}, b_{y}, b_{z}\right)$ are flow losses in porous media or across porous baffle plates, and the final condition account for the injection of mass at a source represented by a geometry element. The $u_{w}, v_{w}$ and $w_{w}$ are the velocity of the source components whereas the $u_{s}, v_{s}$ and $w_{s}$ are the velocity of the fluid at the surface of the source relative to the source itself. $\delta$ is the source of pressure where the statics pressure is applied in this research which determine the $\delta=1.0$ Manual [13].

\subsection{Body Motion Equation}

Referring to the geometrical floating jetty, the body motion of the floating jetty is analysed in the global coordinate system, where the motion equations of the rigid floating jetty is expressed in Eqs. (5)-(7):

$$
\begin{aligned}
& \frac{d}{d t}\left(m \vec{v}_{c}\right)=\vec{f} \\
& \frac{d}{d t}\left(M_{c} \cdot \vec{w}_{c}\right)=\vec{m}_{c}
\end{aligned}
$$

The index $C$ shows the center of mass of the body. $m$ and $M_{c}$ are the body mass and the tensor of the moments of inertia, respectively. The notations of $\vec{\omega}_{c}$ and $\vec{v}_{c}$ are the angular velocity and the velocity vectors, respectively. Meanwhile, $\vec{m}_{c}$ represents the resultant moment vector acting on the body Maki et al., [14]. In addition, $\vec{f}$ is the resultant force which is expressed in Eq. (7).

$$
\vec{f}=\int_{S}(T-\rho I) \cdot \vec{n} d S+\int_{V} \rho_{b} \vec{b} d V+\vec{f} E
$$


Here, $\rho_{b}$ and $f \vec{E}$ are the density of the body and the external forces acting in the body, respectively Yan and Huang [15]. The dynamic fluid body interaction function is applied to simulate the vertical motion (heave and pitch motions) of the floating jetty motion.

\subsection{Waves}

The fifth-order Stokes waves is selected for the current numerical simulation. A regular wave with a wave amplitude of $0.5 \mathrm{~m}$ in head-seas direction was employed incorporated with various wavelengths. The nonlinear wave theory for limited amplitude progressive surface wave is generated through the mesh boundary. This implies that the fluid flow is incompressible and irrotational. The reference system $(x, z)$ is set, where $x$ (positive direction) is the wave propagation direction and $z$ (positive direction) in the upward direction. The wave is mainly characterized by three components i.e., wave-height $\left(H_{w}\right)$, wavelength $(\lambda)$, and wave period $\left(T_{w}\right)$. In addition, the equations of the angular wave frequency $(\omega)$ and the wave celerity $(c)$ and are written as follows;

$\omega=\frac{2 \pi}{T}=c k$ and $c=\frac{\lambda}{T}$

where $k$ is the wave number,

$k=\frac{2 \pi}{\lambda}$

$\nabla^{2} \psi=0$

$u=\frac{\partial \psi}{\partial x}$ and $v=-\frac{\partial \psi}{\partial z}$

The symbol of $\psi$ is the Laplace equation; along with its boundary conditions at the free surface and the bottom, are solved using a perturbation method. Here, the perturbation parameter is the dimensionless wave amplitude $\varepsilon=\frac{k H}{2}$ (as seen in Figure 2).

\subsection{Turbulence Model}

For the stability and efficiency of the numerical computation, Renormalization-group (RNG) turbulence model has wider applicability than the standard $\mathrm{k}-\varepsilon$ model as also applied by Fitriadhy et al., [16], Fitriadhy et al., [17], Fitriadhy and Malek [18] and Fitriadhy et al., [19]. This turbulence model also has considered for low Reynolds number effects Yakhot and Orszag [20], Yakhot et al., [21], Koutsourakis et al., [22] and Li et al., [23] which is known to more accurately describe low intensity turbulence flows with having strong shear regions.

\section{Simulation Condition}

\subsection{Principle Data of Floating Jetty}

The geometry of the floating jetty is clearly shown in Figure 1, which is basically composed of three main components i.e., floater incorporated with structural heave plate, struts and deck structure. The details particular of the floating is completely summarized in Table 1 . In addition, the hydrostatic particulars such as displacement and moment inertia of the floating jetty incorporated 
with and without heave plate are calculated separately using numerical approach. These data are required in the computational simulation, which completely presented in Table 2.

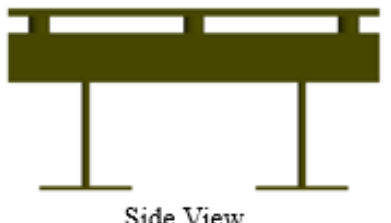

Side View

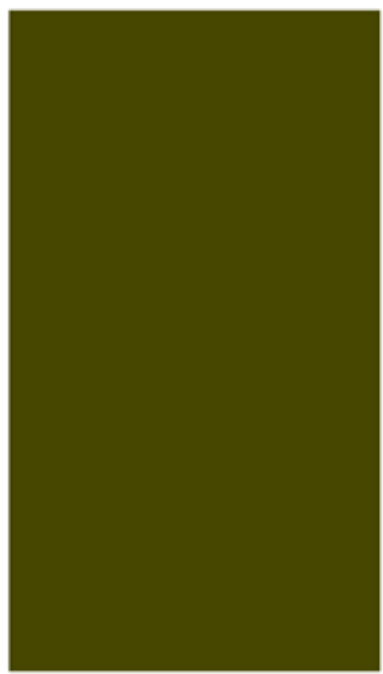

Top View

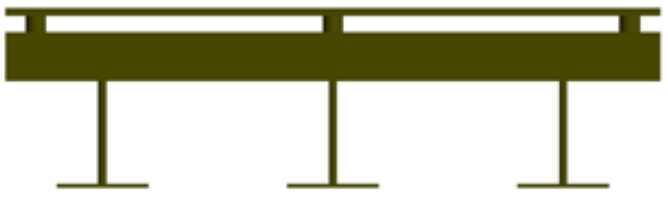

Front View

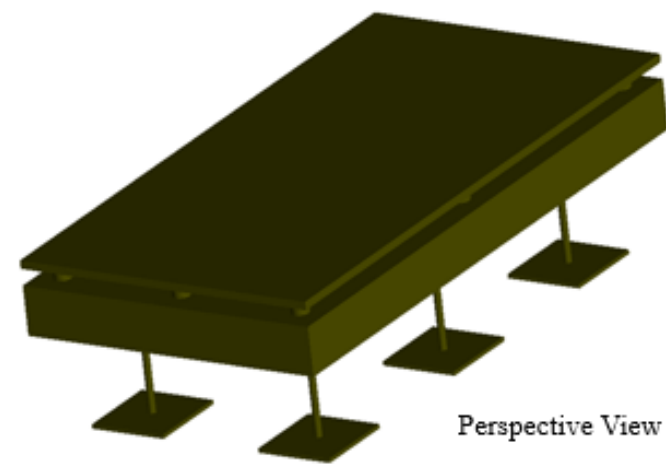

Fig. 1. Geometry of floating jetty incorporated with structural heave plate

Table 1

Principle dimensions of floating jetty

\begin{tabular}{ll}
\hline Descriptions & Dimensions \\
\hline Deck & $9.0 \times 16.0 \times 0.2 \mathrm{~m}$ \\
Structural Deck Support & $0.5 \times 0.5 \times 0.4 \mathrm{~m}$ (9 units) \\
Pontoon & $9.0 \times 16.0 \times 1.2 \mathrm{~m}$ \\
Strut & $0.2 \times 0.2 \times 2.5 \mathrm{~m}$ (6 units) \\
Heave Plate & $2.25 \times 2.25 \times 0.1 \mathrm{~m}$ (6 units) \\
\hline
\end{tabular}

Table 2

Properties of floating jetty with and without heave plate

\begin{tabular}{lll}
\hline \multirow{2}{*}{ Descriptions } & Heave Plate & with \\
\hline Vol. of Displacement $\left(\mathrm{m}^{3}\right)$ & $1.80 \times 10^{2}$ & $2.06 \times 10^{2}$ \\
LCG & $-1.39 \times 10^{-16}$ & $-9.71 \times 10^{-10}$ \\
TCG & 0.000 & 0.000 \\
VCG & $3.99 \times 10^{-1}$ & $5.57 \times 10^{-2}$ \\
LCB & $-1.39 \times 10^{-16}$ & $-9.71 \times 10^{-10}$ \\
TCB & 0.000 & 0.000 \\
VCB & 0.399 & 0.481 \\
$I_{x x}$ & $2.47 \times 10^{6}$ & $2.98 \times 10^{6}$ \\
$I_{x z}$ & $1.22 \times 10^{-11}$ & $1.63 \times 10^{-4}$ \\
$I_{y y}$ & $6.97 \times 10^{5}$ & $1.13 \times 10^{6}$ \\
$I_{z z}$ & $3.07 \times 10^{6}$ & $3.72 \times 10^{6}$ \\
\hline
\end{tabular}




\subsection{Parametric Studies}

In the current CFD simulation, the effect of the various wave periods (T) from 3 seconds up to 10 seconds have been employed as obviously summarised in Table 3 . Here, the wave amplitude (A) of $0.25 \mathrm{~m}$ is set to be constant.

Table 3

Matrix of computational simulations

\begin{tabular}{llllllllll}
\hline Structure of Floating Jetty & Draft & \multicolumn{10}{c}{ Wave Period (s) } \\
& $(\mathrm{m})$ & 3 & 4 & 5 & 6 & 7 & 8 & 9 & 10 \\
\hline w/o Heave Plate & 0.8 & $\mathrm{~V}$ & $\mathrm{~V}$ & $\mathrm{~V}$ & $\mathrm{~V}$ & $\mathrm{~V}$ & $\mathrm{~V}$ & $\mathrm{~V}$ & $\mathrm{~V}$ \\
& 0.4 & $\mathrm{~V}$ & $\mathrm{~V}$ & $\mathrm{~V}$ & $\mathrm{~V}$ & $\mathrm{~V}$ & $\mathrm{~V}$ & $\mathrm{~V}$ & $\mathrm{~V}$ \\
Heave Plate & 0.8 & $\mathrm{~V}$ & $\mathrm{~V}$ & $\mathrm{~V}$ & $\mathrm{~V}$ & $\mathrm{~V}$ & $\mathrm{~V}$ & $\mathrm{~V}$ & $\mathrm{~V}$ \\
\hline
\end{tabular}

\subsection{Computational Domain and Boundary Conditions}

The boundary conditions of the computational domain and meshing modelling are presented in Figure 2. Referring to the main mesh block, the boundary condition at $X_{\min }$ is assigned as wave; while $X_{\max }$ is defined as outflow boundary, which is purposed to absorb the wave motion and reduce the reflection from the boundary as seen in Figure 2 (left). The boundary conditions of $Y_{\min }, Y_{\max }$ and $Z_{\min }$ are assigned as the symmetry boundaries, which apply zero-gradient conditions; meanwhile, the boundary of $Z_{\max }$ is the specified pressure to create a uniform pressure in the boundary. All boundary conditions for the nested mesh blocks are defined as the symmetries. The detailed boundary conditions are completely presented in Table 4. Each of the boundary conditions is shown in the main mesh block and nested mesh blocks.

Table 4

Boundary conditions

\begin{tabular}{lll}
\hline Boundary & Main Mesh Block & Nested Mesh Blocks \\
\hline$X_{\min }$ & Wave (WV) & Symmetry \\
$X_{\max }$ & Outflow (O) & Symmetry \\
$Y_{\min }$ & Symmetry (S) & Symmetry \\
$Y_{\max }$ & Symmetry (S) & Symmetry \\
$Z_{\min }$ & Symmetry (S) & Symmetry \\
$Z_{\max }$ & Specified Pressure (P) & Symmetry \\
\hline
\end{tabular}

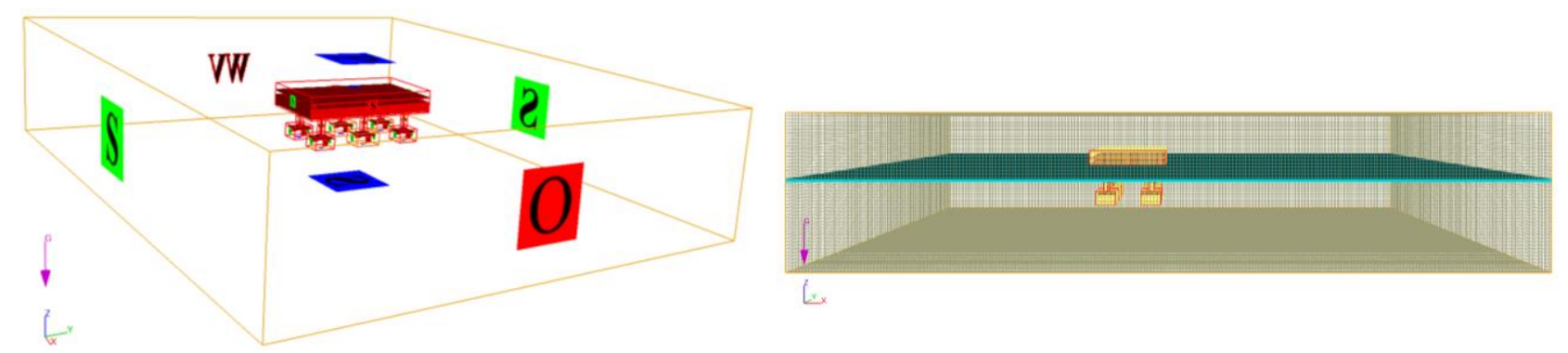

Fig. 2. Boundary condition (left) and mesh generation (right)

The meshing generation is created in Flow-3D as clearly shown in Figure 2 (right). An extra refinement of the mesh model called nested block is then added to increase the meshing quality. It should be noted here that the floating jetty was assigned as the full-scale dimension model incorporated with two degrees of freedom (heave and pitch motions). Here, the mesh convergence 
study has been conducted to preserve the steadiness in the computational simulation results as presented in Table 5. Referring to this mesh independent results, the total cell meshing of 1,827,052 has been selected in all computational simulations of the floating jetty model. For this reason, it was unnecessary to increase the total cell meshing up to 2,207,034 due to its insignificant influence into the computational results of the magnitude of the heave motion amplitude. Besides, the time history for the heave motions of the floating jetty at wave periods of 4 seconds is presented in Figure 3 . Furthermore, a package software in Flow Sight is utilised to visualise the 3D-floating jetty model in waves as displayed in Figure 4.

Table 5

Mesh convergence study

\begin{tabular}{lll}
\hline Case & Total Number of Cell & Amplitude of Heave Motion $(\mathrm{m})$ \\
\hline$A$ & 885,563 & 0.1091 \\
$B$ & $1,330,800$ & 0.0965 \\
$C$ & $1,827,052$ & 0.0933 \\
$D$ & $2,207,034$ & 0.0930 \\
\hline
\end{tabular}

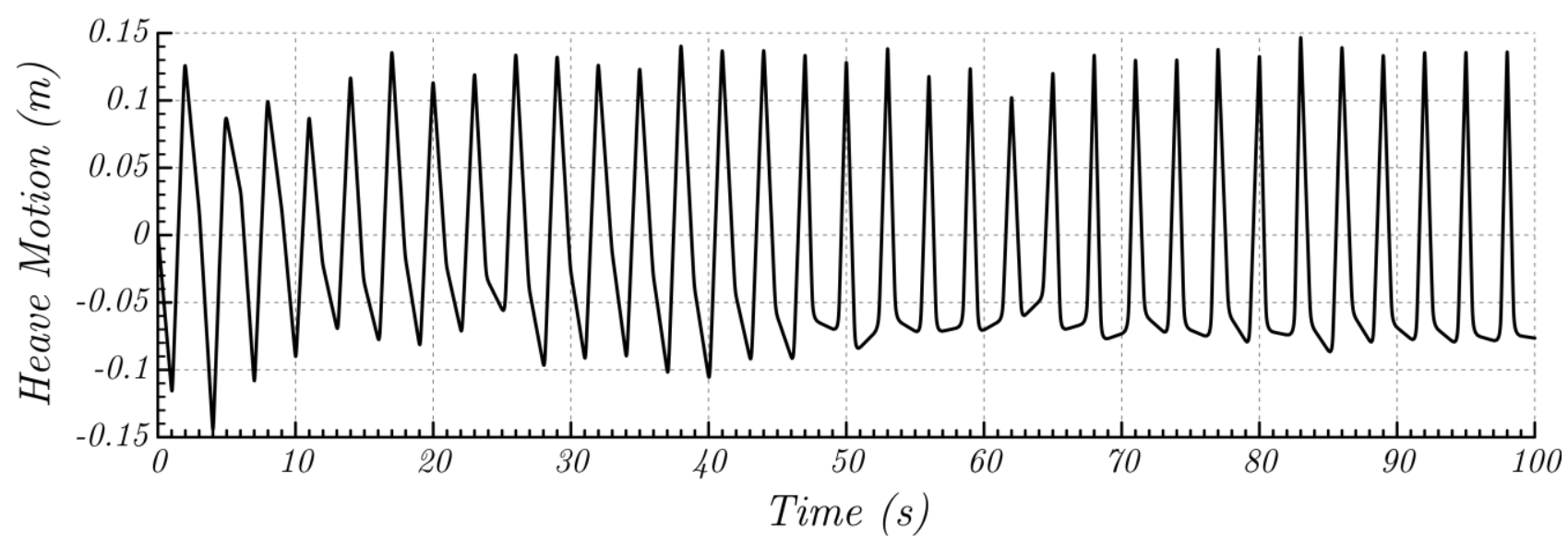

Fig. 3. Time history for heave motions of floating jetty at wave period of 4 seconds

\begin{tabular}{cccc}
\multicolumn{4}{c}{ Wave Elevation (m) } \\
\hline-0.50 & -0.17 & 0.17 & 0.50
\end{tabular}

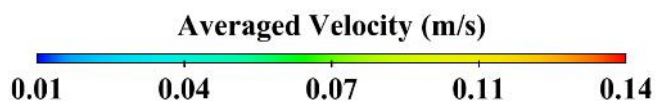
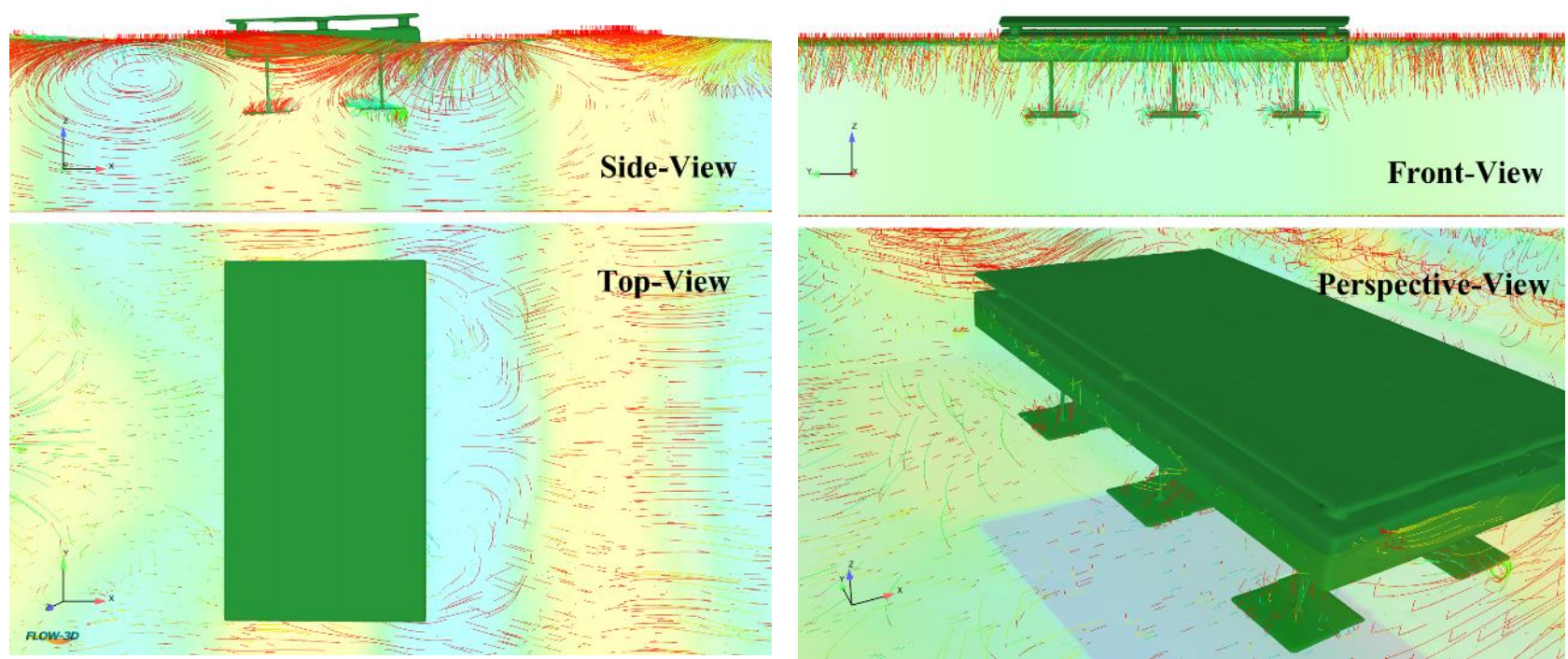

Fig. 4. Example CFD visualisation of floating jetty performances at wave periods of 4 seconds 


\section{Results and Discussion}

The characteristics of the heave motion responses of the floating jetty incorporated with the heave plate $(D=0.8 \mathrm{~m}$ ) has been shown in Figure 5 . In general, the RAO of its heave motion has gradually increased within the range of the wave periods $3 \leq T_{w} \leq 7$ seconds. However, the results have been inversely proportional as the wave periods further increases up to 10 seconds. In the other words, the amplitude of heave motion of the floating jetty has been adequately decreased at the longer wave periods. Referring to presence of the heave plate, the floating jetty experiences a more significant reduction of the heave motion oscillations as compared to the floating jetty without heave plate particularly at $T_{w}=8$ and 9 seconds. As seen in Figure 6 , the floating jetty incorporated with heave is more stable due less heave oscillation motions as well as the heave damping coefficient increased. It should be noted that the maximum percentage of the heave motion reduction of the floating jetty incorporated with the heave plate is about $20.2 \%$, which occurs at $T_{w}=9$ seconds (see Table 6). This can be explained by the fact that the heave plate provided more heave damping coefficient as also noted by Chakrabarti [2] and Li et al., [23]. Referring to the CFD simulation results, it is fairly concluded that the heave plate has sufficiently suppressed the heave motions of the floating jetty especially in the longer wave periods condition, which was similar to what reported by Fitriadhy et al., [24] and Fitriadhy and Adam [25].

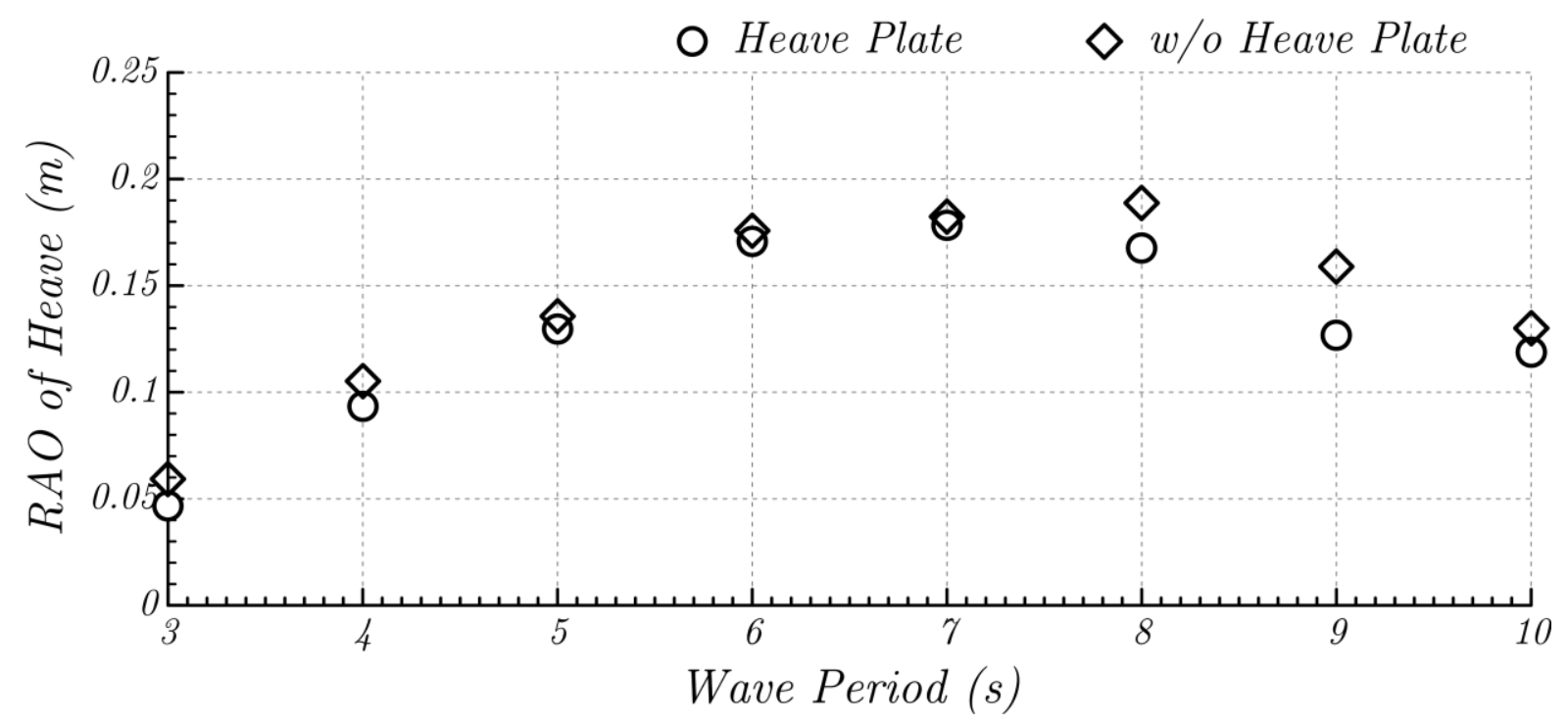

Fig. 5. Heave motion characteristics with and without heave plate at various wave periods

Table 6

Heave motions of floating jetty with and without heave plate at various wave periods

\begin{tabular}{lll}
\hline \multirow{2}{*}{ Wave period $(\mathrm{s})$} & \multicolumn{2}{l}{ Amplitude of Heave Motion, $(\mathrm{m})$} \\
& w/o Heave Plate & Heave Plate \\
\hline 3 & 0.0592 & 0.0466 \\
4 & 0.1052 & 0.0933 \\
5 & 0.1356 & 0.1297 \\
6 & 0.1757 & 0.1707 \\
7 & 0.1825 & 0.1783 \\
8 & 0.1888 & 0.1677 \\
9 & 0.1589 & 0.1268 \\
10 & 0.1301 & 0.1189 \\
\hline
\end{tabular}




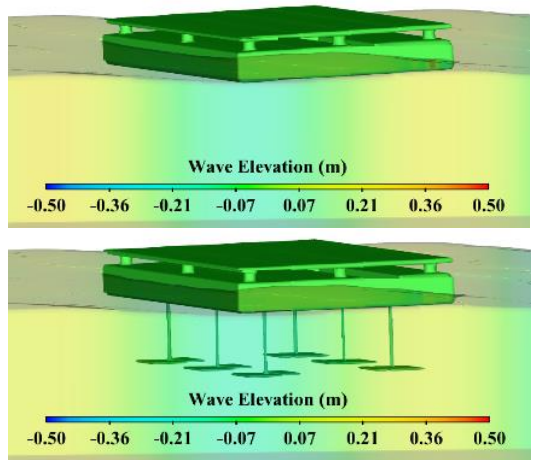

(a)

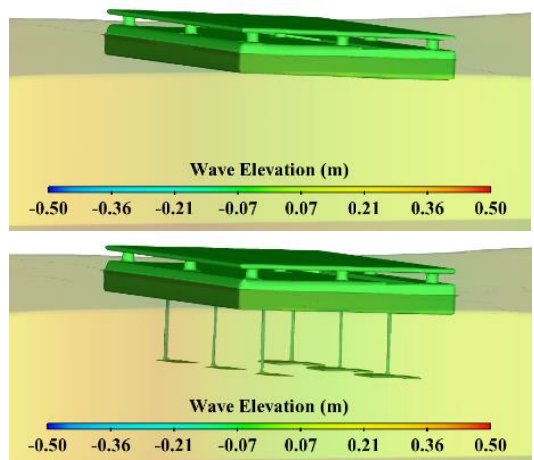

(b)

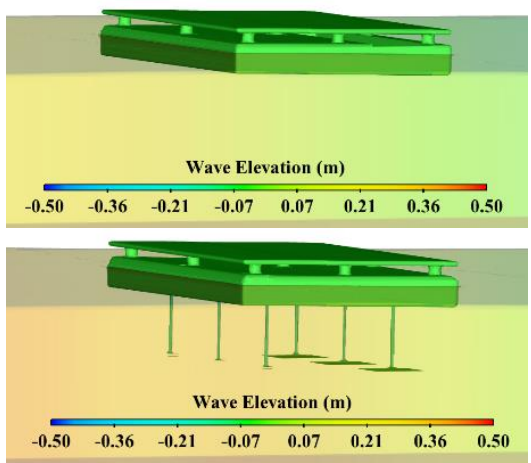

(c)

Fig. 6. Wave elevation characteristics of floating jetty without (above) and with (below) heave plates at various wave periods for (a) $T_{w}=3 s,(b) T_{w}=6 s$ and (c) $T_{w}=9 s$

The characteristics of the heave motion responses of the floating jetty incorporated with heave plate at the various drafts (D) have been displayed in Figure 7. Basically, the increase of the draft from $0.4 \mathrm{~m}$ to 0.8 has resulted in the reduction of the heave motion amplitude from $0.1958 \mathrm{~m}$ and $0.1783 \mathrm{~m}$. In the other words, the RAO's reduction of the heave motion is about $8.9 \%$ at wave-period of $T_{w}=7$ seconds. This occurred since the added mass and damping coefficients of the current floating jetty have gradually increased as also well-reported by Koh and Cho [7]. Similar to what was reported by Liu et al., [26], inherently, this floating jetty was more stable. The visualization of the floating jetty performances with respect to the wave elevation characteristics have been displayed clearly in Figure 8. Although the increase of the draft of the current floating jetty was insignificant, the magnitude of the heave motion has subsequently reduced as summarised completely in Table 7. It is merely concluded that the presence of the heave plate on the floating jetty has been relatively more significant influence towards reducing the amplitude of its heave motion as compared with the case of the deeper draft condition.

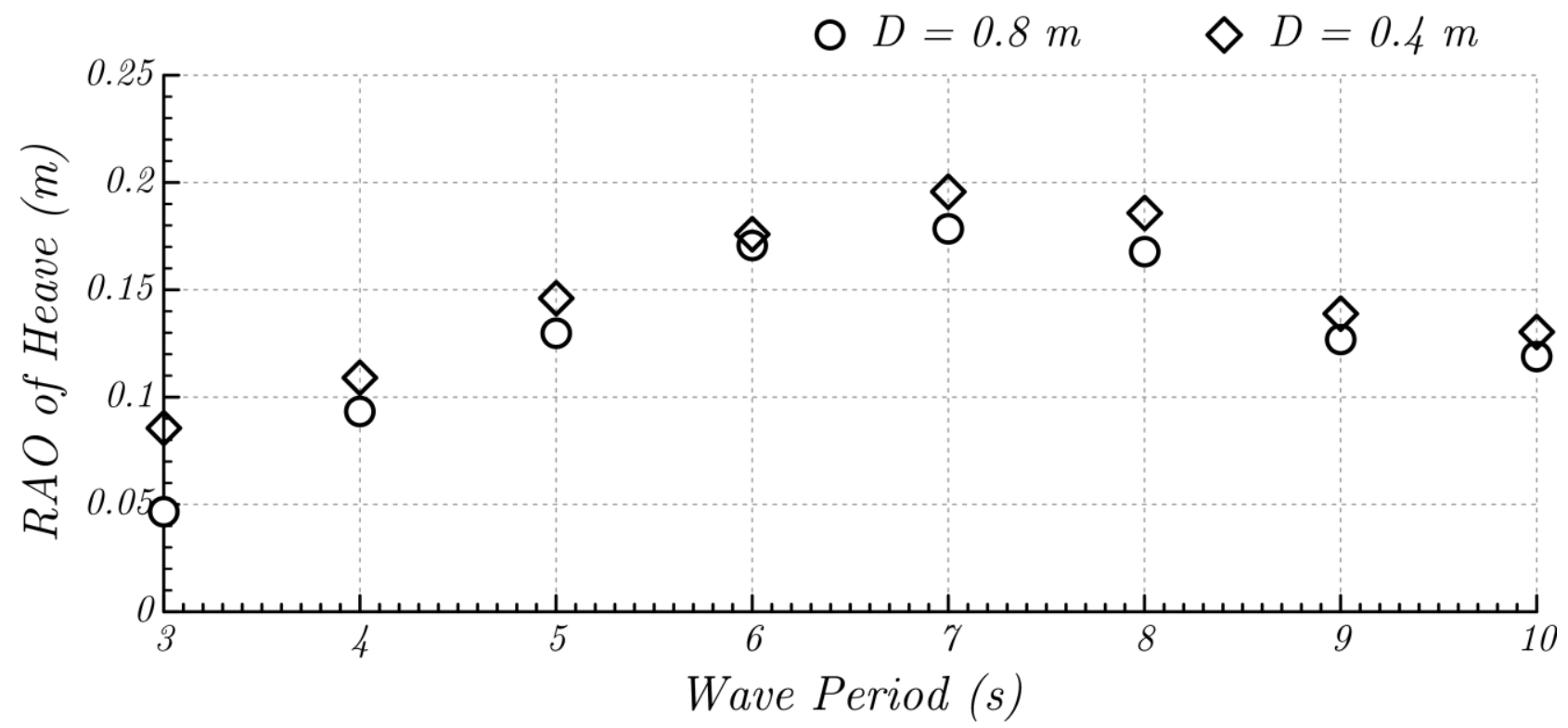

Fig. 7. Heave motion characteristics of floating jetty with and without heave plate at various drafts 


\section{Table 7}

Heave motion responses of floating jetty incorporated with heave plate at various drafts

\begin{tabular}{lll}
\hline Wave Period $(\mathrm{s})$ & $\begin{array}{l}\text { Amplitude of Heave Motion, }(\mathrm{m}) \\
\mathrm{D}=0.4 \mathrm{~m}\end{array}$ \\
\hline 3 & 0.0855 & $0.8 \mathrm{~m}$ \\
4 & 0.1089 & 0.0466 \\
5 & 0.1460 & 0.0933 \\
6 & 0.1759 & 0.1297 \\
7 & 0.1958 & 0.1707 \\
8 & 0.1857 & 0.1783 \\
9 & 0.1389 & 0.1677 \\
10 & 0.1304 & 0.1268 \\
\hline
\end{tabular}

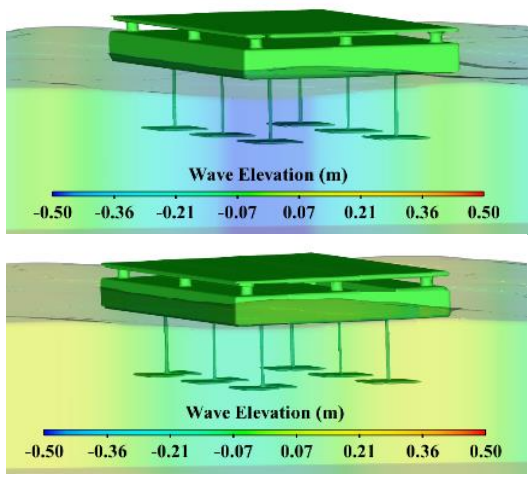

(a)

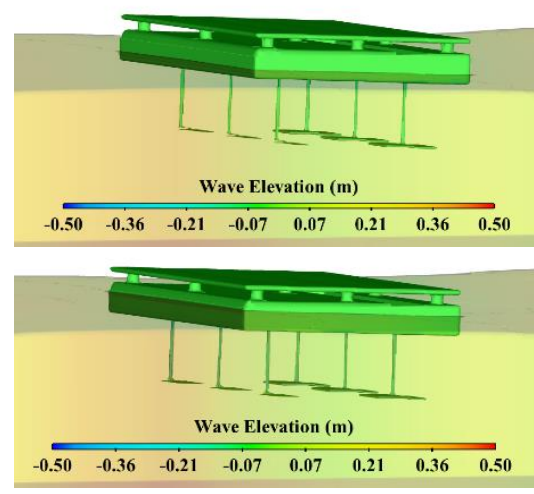

(b)

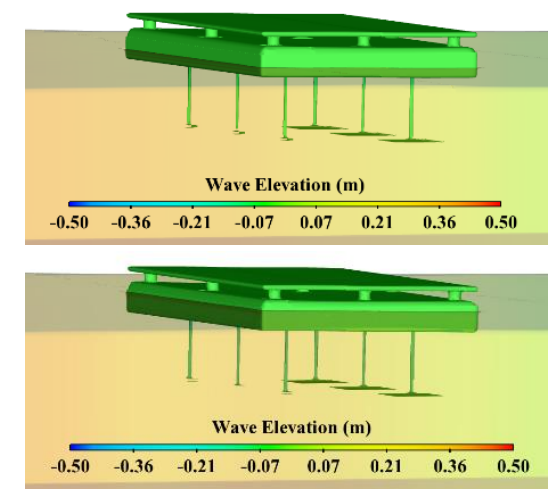

(c)

Fig. 8. Wave elevation characteristics of floating jetty incorporated with heave plate in different drafts; 0.4 $\mathrm{m}$ (above) and $0.8 \mathrm{~m}$ (below) at various wave periods for (a) $T_{w}=3 \mathrm{~s}$, (b) $T_{w}=6 \mathrm{~s}$ and (c) $T_{w}=9 \mathrm{~s}$

\section{Conclusion}

The CFD investigation into the effect of heave plate on vertical motion responses of a floating jetty has been successfully performed. Several parameters such as effect of various wave periods and drafts of the floating jetty have been taken into account in the computational simulation. The simulation results are then presented in the form of its Responses Amplitude Operator (RAO), which can be drawn as follows:

i. As compared with case without the heave plate, in general, the floating jetty equipped with the heave plate sufficiently suppresses the amplitude of her heave motion responses, where the maximum reduction of the RAO of heave motion is about $20.2 \%$ at wave period of $T_{w}=7$ seconds.

ii. Although the increase of the floating jetty's draft up to $0.8 \mathrm{~m}$ is insignificant, it results in further reduction of its heave motion amplitude about $8.9 \%$ with regard to the draft of $0.4 \mathrm{~m}$.

\section{Acknowledgement}

The authors wish to greatly thank to Translational Research Grant Scheme (TRGS), VOT. Number: 53305 for providing research funding to this project.

\section{References}

[1] Niaounakis, Michael. Management of Marine Plastic Debris. William Andrew, 2017.

[2] Chakrabarti, Subrata. Handbook of Offshore Engineering (2-volume set). Elsevier, 2005. 
[3] Holmes, Samuel, Shankar Bhat, Pierre Beynet, Anil Sablok, and Igor Prislin. "Heave plate design with computational fluid dynamics." J. Offshore Mech. Arct. Eng. 123, no. 1 (2001): 22-28.

https://doi.org/10.1115/1.1337096

[4] Brown, Adam, Jim Thomson, and Curtis Rusch. "Hydrodynamic coefficients of heave plates, with application to wave energy conversion." IEEE Journal of Oceanic Engineering 43, no. 4 (2017): 983-996.

[5] Liang, Hai-zhi, Kun Liu, Lu-yu Li, and Jin-ping Ou. "Dynamic performance analysis of the tuned heave plate system for semi-submersible platform." China Ocean Engineering 32, no. 4 (2018): 422-430.

https://doi.org/10.1007/s13344-018-0044-7

[6] Tao, Longbin, and Shunqing Cai. "Heave motion suppression of a Spar with a heave plate." Ocean Engineering 31, no. 5-6 (2004): 669-692.

https://doi.org/10.1016/j.oceaneng.2003.05.005

[7] Koh, Hyeok-Jun, and I. H. Cho. "Motion response of a circular cylinder with a heave plate in waves." In The Twentyfirst International Offshore and Polar Engineering Conference. International Society of Offshore and Polar Engineers, 2011.

[8] Subbulakshmi, A., Jithin Jose, R. Sundaravadivelu, and R. Panneer Selvam. "Effect of viscous damping on hydrodynamic response of spar with heave plate." Aquatic Procedia 4 (2015): 508-515.

https://doi.org/10.1016/i.aqpro.2015.02.066

[9] $\mathrm{Yu}$, Chenfang, Zhiqiang $\mathrm{Hu}$, and Shisheng Wang. "Investigation of heave response of the deepwater octagonal FDPSO using various heave plate configurations." Journal of Marine Science and Application 16, no. 4 (2017): 446457. https://doi.org/10.1007/s11804-017-1431-9

[10] Mecrow, Robert, and Seamus Garvey. "Hydrodynamic Performance of Conical Shaped Heave Plates." In 2019 Offshore Energy and Storage Summit (OSES), pp. 1-9. IEEE, 2019. http://doi.org/10.1109/OSES.2019.8867352

[11] Ishihara, Takeshi, Muhammad Bilal Waris, and Hiroyuki Sukegawa. "A study on influence of heave plate on dynamic response of floating offshore wind turbine system." In Proc. of European Offshore Wind Conference \& Exhibition. 2009.

[12] Sapee, S. "Computational Fluid Dynamics Study on Droplet Size of Kerosene Fuel." Journal of Advanced Research in Fluid Mechanics and Thermal Sciences 16, no. 1 (2015): 1-14.

[13] Manual, Flow3D User. "Flow3D User Manual, v9. 4.2, Flow Science." Inc., Santa Fe, NM (2011).

[14] Maki, Kevin J., Riccardo Broglia, Lawrence J. Doctors, and Andrea Di Mascio. "Numerical investigation of the components of calm-water resistance of a surface-effect ship." Ocean engineering 72 (2013): 375-385. https://doi.org/10.1016/i.oceaneng.2013.07.022

[15] Sisong, Yen, and Huang Genyu. "Dynamic performance of towing system-simulation and model experiment." In OCEANS 96 MTS/IEEE Conference Proceedings. The Coastal Ocean-Prospects for the 21st Century, vol. 1, pp. 216230. IEEE, 1996.

[16] Fitriadhy, Ahmad, Nur Adlina Aldin, and Nurul Aqilah Mansor. "CFD Analysis on Course Stability of a Towed Ship Incorporated with Symmetrical Bridle Towline." CFD Letters 11, no. 12 (2019): 88-98.

[17] Fitriadhy, Ahmad, Nurul Aqilah Mansor, Nur Adlina Aldin, and Adi Maimun. "CFD Analysis on Course Stability of An Asymmetrical Bridle Towline Model of a Towed Ship." CFD Letters 11, no. 12 (2019): 43-52.

[18] Fitriadhy, A., and A. M. A. Malek. "Computational fluid dynamics analysis of a ship's side launching in restricted waters." Journal of Mechanical Engineering and Sciences 11, no. 4 (2017): 2993-3003. https://doi.org/10.15282/imes.11.4.2017.3.0269

[19] Fitriadhy, A., M. A. Faiz, and S. F. Abdullah. "Computational fluid dynamics analysis of cylindrical floating breakwater towards reduction of sediment transport." J. Mech. Eng. Sci. 11, no. 4 (2017): 3072-3085. https://doi.org/10.15282/imes.11.4.2017.10.0276

[20] Yakhot, Victor, and Steven A. Orszag. "Renormalization group analysis of turbulence. I. Basic theory." Journal of scientific computing 1, no. 1 (1986): 3-51. https://doi.org/10.1007/BF01061452

[21] Yakhot, A., S. Rakib, and W. S. Flannery. "Low-Reynolds number approximation for turbulent eddy viscosity." Journal of scientific computing 9, no. 3 (1994): 283-292. https://doi.org/10.1007/BF01575033

[22] Koutsourakis, Nektarios, John G. Bartzis, and Nicolas C. Markatos. "Evaluation of Reynolds stress, k- $\varepsilon$ and RNG k- $\varepsilon$ turbulence models in street canyon flows using various experimental datasets." Environmental fluid mechanics 12, no. 4 (2012): 379-403.

https://doi.org/10.1007/s10652-012-9240-9 
[23] Li, Binbin, Zhenhua Huang, Ying Min Low, and Jinping Ou. "Experimental and numerical study of the effects of heave plate on the motion of a new deep draft multi-spar platform." Journal of marine science and technology 18, no. 2 (2013): 229-246. https://doi.org/10.1007/s00773-012-0203-0

[24] Fitriadhy, A., N. Razali, and N. AqilahMansor. "Seakeeping performance of a rounded hull catamaran in waves using CFD approach." Journal of Mechanical Engineering and Sciences 11, no. 2 (2017): 2601-2614. https://doi.org/10.15282/imes.11.2.2017.4.0238

[25] Fitriadhy, A., and N. Amira Adam. "Heave and pitch motions performance of a monotricat ship in headseas." International Journal of Automotive and Mechanical Engineering 14 (2017): 4243-4258. https://doi.org/10.15282/ijame.14.2.2017.10.0339

[26] Liu, Xianqing, Puyang Zhang, Mingjie Zhao, Hongyan Ding, and Conghuan Le. "Influencing Factors of Motion Responses for Large-Diameter Tripod Bucket Foundation." Applied Sciences 9, no. 22 (2019): 4957. https://doi.org/10.3390/app9224957 